\title{
Risk Preference Theory and Family Portfolio-The Evidence from Chinese Household Finance Survey
}

\section{Yi-Chen DONG*}

\author{
College of Literature, Science, and the Arts, University of Michigan Ann Arbor, Michigan,USA \\ dongyc@umich.edu \\ ${ }^{*}$ Corresponding author
}

Keywords: Risk preference, Expect, Family portfolio.

\begin{abstract}
This paper studies the factors that influence the Chinese family investment portfolio based on the traditional Sharpe investment theory, the traditional budget constraint subdivided in two aspects of income and wealth, add the forecast factors, combined with Chinese Household Finance Survey micro database to carry on the empirical analysis, the results showed that in addition to the risk attitude of family wealth factor has a significant effect on the portfolio, and expected rates of change on the influence of domestic securities investment is not significant.
\end{abstract}

\section{Introduction}

In our country, the family portfolio problem is scholars focused problem for a long time. Reasonable family portfolio can not only help families to achieve assets value, resist risk, more has a good effect to the whole macroeconomic operation. Under the economic environment of the new normal, if government wants to release the residents' consumption ability, it needs to research factors affecting domestic portfolio, based on the traditional investment decision theory on the basis of Sharp subdivide the budget constraints, also joined the expected factors, trying to combine Chinese situation analysis of the influence factors of Chinese family investment portfolio.

\section{Literature Review}

The existing literature of the problem of risk attitude and the portfolio can be divided into two kinds, one kind is to study the formation of risk attitude and its influencing factors, typical literature for Junlin Chen in his paper "emergency environment under time pressure and decision makers risk attitude of decision-making behavior experimental study on the influence of" study of risk attitude and the influence of time pressure for decision making, based on the adaptation of the DOSPERT scale of data, using the prospect theory to measure, found in the field of emergency risk attitude is measurable, characterized by risk aversion, and do not agree with conventional areas of risk attitude[1]. Haiyuan Yin in the paper "individual characteristics, access to information and risk attitude" in investor risk appetite status and its influencing factors were studied, based on 733 stock investors in six cities in China survey data, using logit model are analyzed. The authors found that personal wealth such as personal traits significantly affect investor risk appetite, rich sources of information will improve investor risk appetite [2]. Tao Li in the paper, "risk attitude and stock investment" in the study of the social interaction of resident's influence on the stock investment risk attitude, 15 cities in China based on 2007 residents' investment behavior survey data for empirical analysis [3].The authors found that social interaction can affect people's risk attitude in different degrees and participate in stock investment, outstanding performance for interactive the residents of the low degree of risk aversion and participate in a significant inverse relationship between stock. Shiyu Xie on the paper, "two risk attitude experimental research and comparative analysis of" the two-risk attitude in Shanghai is studied the experimental results, based on two risk attitude experimental data of the buyer and the seller of the empirical analysis, found the winning probability and bonus amount will affect the buyer and the seller's risk attitude [4]. The author 
confirms the incentive effects on risk attitudes, the existence of the endowment effect and learning effect.

Another kind of article is to study the Angle of the portfolio and its influencing factors to the analysis of the relationship between risk and investment, representative literature such as Linwan Zhang in his paper "risk attitude and residents' wealth" in the study the relationship between residents' appetite for risk and wealth in China, based on the "city of investor behavior survey", in constructing the index of absolute and relative risk attitude is analyzed [5]. The authors found that residents of absolute risk aversion coefficient is decreasing wealth, relative risk aversion coefficient is increasing function of wealth, the wealth of change can affect the background level of risk of the investors, which in turn affect people's risk attitude. Hong Zhou in the paper, "risk attitudes, financial market consumer financial education and family to participate in" research in the consumer financial education affect their attitude to risk and financial market participation problem, based on household consumption financial investigation data in 2012, tsinghua university, using Logit and probit model are analyzed [6]. The authors found that financial education can significantly improve the family to participate in the probability of financial markets, to distinguish the family risk types can be better implementation of financial education. Yajun Li in the paper, "risk attitude research on the influence of Chinese family investment diversification" of incomplete diversification is studied in reason, based on the 2000 China 15 provinces urban investment behavior survey data, carries on the analysis from the perspective of investors' risk attitude, found the risk attitude of the Chinese family has remarkable effect on the composition of the portfolio and risk aversion degree negative correlation with the probability of holding a diversified portfolio [7]. Tao Li in the paper, "personality traits and stock investment" the head of the household personality characteristics are studied in the stock investment for the family influence, based on the 2010 and 2012 Chinese families track cross section data of "big five" personality classification information for analysis. The author found that the opening dimension of personality characteristics of family stock investment with a steady and significant positive impact [8]. Juan Liao in the paper, "human capital investment risk and the choice of education" risk and income of the higher education is studied on individual choice university relations, based on the distribution of income in China urban household survey data in 2002, with bright income equation and probit regression method is analyzed [9]. The author found that the higher education investment risks and benefits of no decisive influence on education of ordinary high school student choice, individual risk aversion attitude to choose to have significant positive influence on higher education. Tao Li in his paper "attitude to risk and stock investment" in social interaction was studied in resident's influence on the stock investment risk attitude, 15 cities in China based on 2007 residents' investment behavior survey data for empirical analysis [8]. The authors found that social interaction can affect people's risk attitude in different degrees and participate in stock investment, outstanding performance for interactive the residents of the low degree of risk aversion and participate in a significant inverse relationship between stock. Xiuli Zhang in the paper, "the individual attitude to the risk of stock investment study" individual for stock investment is studied in the attitude, based on the student questionnaire to carry on the empirical analysis of experimental data [10]. The author falsified the traditional theory of "the individual's risk aversion" this view, that the individual pursuit for stock investment is a risk, and the two reference points outside the interval preference for risk.

\section{Methodology and Data}

Traditional investment theory thinks that rational families choose diversification investment strategy, sharp's portfolio model is a typical representative of this kind of point of view, sharp think family diversified portfolio strategy the restriction of the two aspects, the first is the restriction of budget constraints, diversified investment can effectively avoid risk, but different assets family its diversified strategy should have differences, the second is a personal preference, the family as a combination of individual also has the "preference", different preferences of families in the face of the same portfolio tend to make a different choice. From sharp's classic portfolio theory, this paper use the multiple linear regression model, combined with micro empirical data analysis, considering 
the sharp of factors influencing the family investment in classical theory at the same time, to join the expected impact on domestic investment combination, get the following equation 1 and equation 2:

$$
y_{i}=\beta_{0}+\beta_{1} \text { risk }+\beta_{2} \text { income }+\beta_{3} \text { wealth }+\beta_{4} X+u
$$

Firstly, this article will income and wealth variables to the regression analysis, respectively, in the case of other family-controlled variable, studying the effect of degree of risk preference of family investment behavior, this article in the analysis of the family investment combination is simplified as two forms:

$$
y_{i}=\beta_{0}+\beta_{1} \text { risk }+\beta_{2} \text { income }+\beta_{3} \text { wealth }+\beta_{4} X+\beta_{5} C+u
$$

Secondly, on the basis of further portfolio for the family to join the family expected factors, including the economic situation, the expected interest rates, and expected price changes for the influence of family investment portfolio, when using least squares regression, this article will return with the above two equations respectively, at the same time, the results are compared and analyzed.

Combined with the research problem and the basic situation of the current micro database, this paper plans to use the China Household Finance Survey (CHFS) as the basis of the microscopic empirical in this paper. CHFS is Chinese family financial investigation and research centers across the country to carry out the sampling survey of project, the main content includes: housing assets, liabilities and financial wealth and credit constraints, income and consumption, social security and insurance, intergenerational transfer payments, demographic characteristics and employment and payment habits and other relevant information. Now, respectively, in 2011, 2013 and 2015 survey three times successfully. In 2011 the first round of the survey sample distribution in over 25 provinces (cities, districts), 80 counties, 320 village (house) committee, sample size is more than 8000 families. In 2013, the second round of the sample distribution throughout the country 29 provinces (cities, districts), 262 counties, 1048 village (house) committee, sample size is more than 28000 families. In 2015 the third round of the sample distribution throughout the country 29 provinces (cities, districts), 363 counties, 1439 village (house) committee, sample size is more than 39000 families. Sample size from 2011 is 8438 to expand to 2015 more than 39000 households.

In the process of using CHFS data, this article focuses on the following five kinds of variables, the first is investment behavior variables, including saving behavior and the securities investment behavior, the second is the income variable. Again in this paper, we use the index of total family income, variable is wealth, this article mainly to the family with the number of homes and cars measure, again is macroeconomic factors characteristic variables, the last is expected variables, including the expected interest rate changes and price changes, in the field of China's financial investigation CHFS is relatively in-depth micro database, better depict the behavior of Chinese families in financial markets, the data can meet the needs of this study.

\section{Results}

Based on the least squares regression analysis was carried out on the family investment behavior and its influencing factors, and represented by deposits and securities investment, respectively, considering the prospect of additional expectations and no additional two cases, the comparison of two kinds of results can better depict investment behavior of the family.

Equation 1 and equation 2 of OLS regression results are shown in table below: 
Table 1 Results of OLS regression

\begin{tabular}{|c|c|c|c|c|}
\hline & (1) & (2) & (3) & (4) \\
\hline VARIABLES & stock & stock & savings & savings \\
\hline \multirow[t]{2}{*}{ risk } & $0.0114 * *$ & $0.0107 * *$ & $-15,689$ & $-12,893$ \\
\hline & $(0.00483)$ & $(0.00496)$ & $(12,908)$ & $(10,848)$ \\
\hline \multirow[t]{2}{*}{ income } & $-1.52 \mathrm{e}-08$ & $-5.29 \mathrm{e}-08 * *$ & 0.0160 & 0.149 \\
\hline & $(2.42 \mathrm{e}-08)$ & $(2.49 \mathrm{e}-08)$ & $(0.503)$ & $(0.416)$ \\
\hline \multirow[t]{2}{*}{ house } & $0.0377 * * *$ & $0.0374 * * *$ & $95,935 * * *$ & $86,631 * * *$ \\
\hline & $(0.0101)$ & $(0.0102)$ & $(23,332)$ & $(19,129)$ \\
\hline \multirow[t]{2}{*}{ car } & -0.0309 & $-0.0660 * * *$ & 36,393 & $-55,712$ \\
\hline & $(0.0244)$ & $(0.0251)$ & $(48,464)$ & $(45,853)$ \\
\hline \multirow[t]{2}{*}{ econ } & & $0.0597 * * *$ & & $86,622 * * *$ \\
\hline & & $(0.00935)$ & & $(15,940)$ \\
\hline \multirow[t]{2}{*}{ rate } & & -0.00561 & & $125,069 * * *$ \\
\hline & & $(0.0103)$ & & $(44,682)$ \\
\hline \multirow[t]{2}{*}{ price } & & $-0.0143 *$ & & $-30,114$ \\
\hline & & $(0.00805)$ & & $(19,220)$ \\
\hline \multirow[t]{2}{*}{ Constant } & -0.0190 & -0.0421 & 19,073 & $-265,529 * *$ \\
\hline & $(0.0385)$ & $(0.0484)$ & $(94,784)$ & $(107,128)$ \\
\hline Observations & 831 & 798 & 770 & 770 \\
\hline R-squared & 0.024 & 0.075 & 0.251 & 0.552 \\
\hline
\end{tabular}

Note: Standard errors in parentheses, $* * * \mathrm{p}<0.01, * * \mathrm{p}<0.05, * \mathrm{p}<0.1$

As shown in the table above, the first column and the second column represents the situation of the domestic securities investment, including the first column is not with the securities investment behavior, the second column is additional expected investment behavior of securities; The third column and the fourth column represents household savings investment behavior, including the third column represents no additional expected savings behavior, the fourth column represent additional expected savings behavior. Look from the regression coefficient of the first column, in the case of no additional forecast, the impact on the stock investment behavior is risk attitude and property number, both have positive impact on stock investment, represented by the number of the wealth of the factors on the stock investment more positive role; From the point of the regression coefficient of the second column, risk attitude and wealth after expected factors influences on stock investment direction and the influence of basic remain unchanged. Expected macroeconomic situation get better, to family stock investment has a positive role in promoting, is expected to rise 
in price has negative effect to the stock investment and is significant; The regression results from the third column, risk attitude and negative influence on savings behavior, but not, significantly, in the case of no additional expected, represented by the number of wealth factors more significant effects on saving behavior; From the point of the fourth column of the regression results, after the expected factors, risk attitude for saving is not significant, the influence of a drop in household wealth factors, the change of the expected economic situation and the expected interest rates on savings behavior have significant positive effects, including interest rate changes more influence on savings behavior.

The first column, and comparative analysis of the third column coefficient can reflect the without additional expected family influence factors of portfolio, analysis found that risk factors and wealth effect on domestic investment combination, the largest family wealth factors of property in case of securities investment and saving behavior has a significant positive effect. The second column and the fourth column of the comparative analysis can reflect the additional expected home portfolio behavior, analysis found that risk attitude and wealth factors still play an important role when they decide family portfolio, and the expected economic situation and the expected interest rates to the influence of family investment portfolio is significant, especially the impact on household savings behavior more showed a significant positive role.

Combined with the regression results of the above analysis this paper found that the family of the portfolio structure affected by factors other than expected and expectations, the specific performance as follows:

First, risk attitude, the influence of the traditional sharpe classic theory is that risk appetite families are more prone to high-risk high-yield investment projects, and the risk aversion of the family, by contrast, in this paper, the regression results are basically identical with the theory of sharp, sharp theory is verified conclusions in terms of risk attitude; Secondly, the influence of the budget constraint, this paper, from two angles of income and wealth to consider this question. Found wealth than income factors impact on household investment behavior more and more significant, especially housing quantity factor for both the securities investment behavior and has a play an important effect on saving behaviour. Finally, the forecast factors, this article on the basis of traditional sharpe model joined the expected factors, analysis found that the expected interest rate changes have a positive effect on savings behavior, and the impact on the securities investment behavior is not big, it shows that the securities investment behavior of households in China more is not sensitive to the change of interest rate policy.

\section{Conclusions and Future Research}

Based on an empirical analysis of the Chinese family financial data show that Chinese households' portfolio model and the influence of the traditional investment theory, and has distinct Chinese characteristics, first of all, this paper verifies the classic risk attitude to family investment portfolio decision theory, the influence of the research results show that in comparison with the family of risk appetite, risk aversion families tend to choose more savings such a conservative way of investment, which are consistent with the results of the traditional investment theory, secondly the paper verified the budget constraint effect on domestic investment combination, the study found that compared with current income, represented by the number of wealth accumulation effect on the portfolio is bigger, in the end, this article also verifies the expected price and interest rates expected effect on domestic investment combination, found that changes in interest rates expected to significantly affect the level of household savings, but the impact on the stock investment is not significant.

Due to the limitation of data, in the family investment portfolio problem, this article has carried on the comparative static analysis, the traditional inter-temporal factors expressed in expected factors, on the premise of get more detailed data, this article will further extend the model for the dynamic model, to get closer to the reality of the conclusion. 


\section{Reference}

[1] Junlin Chen Qinxue Li Chunping Zhang Yuke Wang, Emergency environment under time pressure and decision makers risk attitudes influence on decision-making behavior experimental study [J]. Management science in China, no.23, 2015

[2] Haiyuan Yin Zhongmin Li, Individual characteristics, access to information and risk attitude [J], Economic review, 2011

[3] Tao Li Jie Guo, Risk attitude and stock investment [J], Economic studies, no.2, 2009

[4] Shiyu Xie Bibo Sun Hongxin Zhu Jie Qin Junmin Wan, Two risk attitude of experimental research and comparative analysis [J], Financial research, no.11, 2007

[5] Linwan Zhang Weixing Wu, Risk attitude and resident's wealth [J], Financial Research, no.4, 2016

[6] Hong Zhou, Risk attitude, consumer financial education and family financial markets to participate in the $[\mathrm{J}]$, Economic science, no.1, 2015

[7] Yajun Li Zhibing Li Junhua Dong Weixing Wu, The risk attitude of Chinese family investment diversification research $[\mathrm{J}]$, The influence of finance and economics, no.7, 2015

[8] Tao Li Jie Guo, Risk attitude and stock investment [J], Economic studies, no.2, 2009

[9] Juan Liao, Human capital investment risk and the choice of education [J], Beijing university education review, no.3, 2010

[10]Xiuli Zhang Liben Shi, The individual attitude to the risk of stock investment study [J], Mathematical statistics and management, no.2, 2006, 